\title{
Dry rolling/sliding wear of nanostructured bainite
}

\author{
S. Das Bakshi ${ }^{\mathrm{a}}$, A. Leiro ${ }^{\mathrm{b}}$, B. Prakash ${ }^{\mathrm{b}}$, H. K. D. H. Bhadeshia ${ }^{\mathrm{a}}$ \\ ${ }^{a}$ Materials Science and Metallurgy, University of Cambridge, U.K. \\ ${ }^{b}$ Applied Physics and Mechanical Engineering, Luleå University of Technology, Sweden
}

\begin{abstract}
The abrasive wear of carbide-free bainitic steel under dry rolling/sliding conditions has been studied. It is demonstrated that this nanostructure, generated by isothermal transformation at $200^{\circ} \mathrm{C}$, has a resistance to wear that supersedes that of other carbide-free bainitic steels transformed at higher temperatures. The experimental results, in combination with a theoretical analysis of rolling/sliding indicates that under the conditions studied, the role of sliding is minimal, so that the maximum shear stresses during contact are generated below the contact surface. Thus, the hardness following testing is found to reach a maximum below the contact surface. The fine scale and associated strength of the structure combats wear during the running-in period, but the volume fraction, stability and morphology of retained austenite plays a significant role during wear, by work-hardening the surface through phase transformation into very hard martensite.
\end{abstract}

Keywords: dry rolling/sliding, carbide-free bainite, Hertzian contact, X-ray diffraction.

Corresponding Author : S. Das Bakshi, Materials Science and Metallurgy, University of Cambridge, 27 Charles Babbage Road, Cambridge, UK, CB3 0FS, email : sd444@cam.ac.uk, subhankar.dasbakshi@gmail.com.

\section{Introduction}

The wear behaviour of bainitic steels subjected to rolling and sliding conditions has been studied for a variety of circumstances [1-9]. In many instances, the results have indicated that this microstructure does not in general outperform pearlite with similar hardness and loading conditions [3, 10-13], the exception being a $0.04 \mathrm{wt} \% \mathrm{C}$ bainitic steel that had a lower wear rate (rolling-sliding) than less-ductile pearlite of similar strength [2]. The greater wear resistance of pearlite is attributed to the ability of the microstructure to deform during rolling and sliding [12], the work-hardening of the ferritic component $[13,14]$ and the significant presence of hard cementite at the wear surface. In contrast, the interpretation of the response of bainite to similar loading tends to be complicated by the smaller fraction of cementite normally associated with bainitic microstructures, and the presence of residual phases such as martensite and retained austenite [3].

Some of these issues have been reviewed [15, pp. 382-389], but the purpose here is to consider a relatively new two-phase, carbide-free nanostructure consisting of exceptionally fine plates of bainitic ferrite embedded in carbon-enriched retained austenite [16-18]. There now exist many 
different alloy compositions that lead to similar nanostructures, and given hardness levels in excess of $600 \mathrm{HV}$, and good combinations of strength, toughness and ductility, there has been considerable activity in exploring the wear resistance of the structure, under many different conditions, Table 1 $[8,9,19-21]$. While strict comparisons are difficult, there is a general impression from all this research that the nanostructure described above holds promise. Reasons offered for this include the fine scale of the nanostructure $[8,9,19-21]$, and the role of the austenite in preventing crack propagation during sliding [20]. A general conclusion is that the finest structures generated by transformation at the lowest temperatures have the best resistance to dry sliding wear [21]. A recent set of three-body abrasion tests that compared the nanostructured bainite, pearlite and martensite in the same steel indicated quite different wear and surface-damage mechanisms for the three structures, with the bainite being the only one that leads to a hardening of the affected surface $[22]$.

The aim of the present work was to develop a deeper understanding of the dry rolling-sliding wear resistance of nanostructured bainite, using high-resolution characterisation methods combined with mathematical modelling. The steel studied is identical to that in our earlier work on threebody abrasion using silicon carbide particles [22].

\section{Experimental Procedure}

\subsection{Alloy and heat treatment}

The steel was produced as a part of a larger programme of work on the development of nanostructured bainite for commercial engineering-applications. Nine tonnes of material were continuously cast in round sections of $150 \mathrm{~mm}$ diameter with the chemical composition listed in Table 2. Cylindrical discs for wear testing were cut from the cast material using wire-electro-discharge machining, the edges of which would be subjected to rolling contact. The edges were therefore machined to a final average roughness of $\sim 1 \mu \mathrm{m}$. The discs were then heat treated in a sealed tube furnace maintained with a positive pressure of argon. Details of the heat treatment and resulting hardness are also given in Table 2. Low transformation temperature with prolonged heat treatment time helps to achieve uniform microstructure across the wear rings which is essentially free from any residual stress.

\subsection{Wear tests}

Rolling/sliding tests were performed in a UTM 2000 twin-disc machine using $10 \mathrm{~mm}$ thick cylindrical discs of $45 \pm 0.1 \mathrm{~mm}$ diameter. The two discs, when made to contact at their edges during rotation, develop a rectangular area of contact. Because of the surface roughness and geometrical/dimensional tolerance, full contact over the entire length of overlap was never made possible. Theoretically, the contact should first be made between the highest asperities and should gradually increase as the wear progresses. A roll-slide parameter, equal to $\xi=0.95$, was introduced by administering differential velocities between the discs. ${ }^{1}$ This would influence the two normal

\footnotetext{
${ }^{1}$ The parameter is calculated from the difference of circumferential velocities of the two discs. Mathematically, it is $1-(\%$ slip/100).
} 
Table 1: Wear data on the hardest, fine mixtures of bainitic ferrite and austenite reported, focusing on the lowest transformation temperatures used to generate the bainite. The Vickers hardness is also listed, and the chemical compositions are given in wt\%. 'NA' stands for not available. The units of the data quoted from table 6 of [23] have been corrected here.

\begin{tabular}{|c|c|c|c|c|c|c|c|c|c|c|c|c|c|c|c|}
\hline $\mathrm{C}$ & $\mathrm{Si}$ & $\mathrm{Mn}$ & $\mathrm{Cr}$ & Mo & $\mathrm{Ni}$ & $\mathrm{Al}$ & & Hardness & \multicolumn{3}{|l|}{ Test } & \multicolumn{3}{|l|}{ Outcome } & Ref. \\
\hline 0.89 & 1.43 & 0.19 & 0.47 & & & & & 697 & \multicolumn{3}{|c|}{$\begin{array}{l}\text { dry sliding friction, cylindrical- } \\
\text { end against disc }\end{array}$} & \multicolumn{3}{|c|}{$\begin{array}{l}\text { comparable wear to martensite of } \\
\text { unspecified hardness }\end{array}$} & [19] \\
\hline 0.19 & 0.57 & 1.77 & 1.37 & 0.33 & 0.42 & 1.35 & carburised & 625 & \multicolumn{3}{|c|}{$\begin{array}{l}\text { dry sliding friction, cylindrical- } \\
\text { end against disc }\end{array}$} & \multicolumn{3}{|c|}{$\begin{array}{l}\text { comparable wear to martensite of } \\
\text { similar hardness }\end{array}$} & [20] \\
\hline 0.61 & 1.72 & 0.75 & 0.35 & 0.04 & 0.12 & & & 627 & $\begin{array}{l}\text { rolling-sliding } \\
\text { rotating discs }\end{array}$ & $(5 \%)$ & counter- & \multicolumn{3}{|c|}{$\begin{array}{l}\text { specific wear rate } 1.0 \text { to } 1.6 \times \\
10^{-4} \mathrm{~mm}^{3} \mathrm{~N}^{-1} \mathrm{~m}^{-1}\end{array}$} & {$[8]$} \\
\hline 0.83 & 1.56 & 1.37 & 0.81 & & & 1.44 & $0.87 \mathrm{~W}$ & 685 & \multicolumn{3}{|c|}{$\begin{array}{l}\text { dry sliding friction, cylindrical- } \\
\text { end against disc }\end{array}$} & \multicolumn{3}{|c|}{$\begin{array}{l}\text { much greater wear resistance } \\
\text { than harder tempered-martensite }\end{array}$} & {$[21]$} \\
\hline 0.99 & 1.50 & 0.76 & 0.46 & & & & & 660 & $\begin{array}{l}\text { rolling-sliding } \\
\text { rotating discs }\end{array}$ & $(5 \%)$ & counter- & $\begin{array}{l}\text { specific wear rate } \\
10^{-4} \mathrm{~mm}^{3} \mathrm{~N}^{-1} \mathrm{~m}^{-1}\end{array}$ & 1.1 & & {$[9]$} \\
\hline 0.98 & 2.90 & 0.77 & 0.45 & & & & & 630 & $\begin{array}{l}\text { rolling-sliding } \\
\text { rotating discs }\end{array}$ & $(5 \%)$ & counter- & $\begin{array}{l}\text { specific wear rate } \\
10^{-4} \mathrm{~mm}^{3} \mathrm{~N}^{-1} \mathrm{~m}^{-1}\end{array}$ & 0.9 & & {$[9]$} \\
\hline 0.90 & 1.65 & 0.79 & 0.48 & & & & & 693 & $\begin{array}{l}\text { rolling-sliding } \\
\text { rotating discs }\end{array}$ & $(5 \%)$ & counter- & $\begin{array}{l}\text { specific wear rate } \\
10^{-4} \mathrm{~mm}^{3} \mathrm{~N}^{-1} \mathrm{~m}^{-1}\end{array}$ & 0.4 & $\times$ & {$[9]$} \\
\hline 0.68 & 1.60 & 1.25 & 1.50 & & & & & 589 & $\begin{array}{l}\text { rolling-sliding } \\
\text { rotating discs }\end{array}$ & $(5 \%)$ & counter- & $\begin{array}{l}\text { specific wear rate } \\
10^{-4} \mathrm{~mm}^{3} \mathrm{~N}^{-1} \mathrm{~m}^{-1}\end{array}$ & 1.0 & $\times$ & {$[9]$} \\
\hline 0.99 & 2.47 & 0.74 & 0.97 & 0.03 & & & & 650 & $\begin{array}{l}\text { rolling-sliding } \\
\text { rotating discs }\end{array}$ & $(5 \%)$ & counter- & $\begin{array}{l}\text { specific wear rate } \\
10^{-6} \mathrm{~mm}^{3} \mathrm{~N}^{-1} \mathrm{~m}^{-1}\end{array}$ & 8.6 & $\times$ & [23] \\
\hline 0.67 & 1.67 & 1.31 & 1.73 & 0.15 & & & $0.12 \mathrm{~V}$ & NA & $\begin{array}{l}\text { rolling-sliding } \\
\text { rotating discs }\end{array}$ & $(5 \%)$ & counter- & $\begin{array}{l}\text { specific wear rate } \\
10^{-5} \mathrm{~mm}^{3} \mathrm{~N}^{-1} \mathrm{~m}^{-1}\end{array}$ & 1.2 & $\times$ & {$[23]$} \\
\hline
\end{tabular}


Table 2: Chemical composition (wt \%), heat treatment and resultant hardness.

\begin{tabular}{cccccccccccccc}
\hline $\mathrm{C}$ & $\mathrm{Mn}$ & $\mathrm{P}$ & $\mathrm{S}$ & $\mathrm{Si}$ & $\mathrm{Al}$ & $\mathrm{Cu}$ & $\mathrm{Cr}$ & $\mathrm{Mo}$ & $\mathrm{V}$ & $\mathrm{Co}$ & $\mathrm{Sn}$ & $\mathrm{Nb}$ \\
0.83 & 2.28 & 0.011 & 0.008 & 1.9 & 0.044 & 0.12 & 1.44 & 0.24 & 0.11 & 1.55 & 0.019 & 0.023 \\
\multicolumn{4}{c}{ Heat Treatment } \\
\multicolumn{4}{c}{$930^{\circ} \mathrm{C}$ 1h, air cooled to $200{ }^{\circ} \mathrm{C}$, held for 10 days, air cooled } & \multicolumn{3}{c}{$622 \pm 13$} \\
\hline
\end{tabular}

stress and the shear stress component in plane stress condition. The tests were conducted in a controlled environment $\left(\sim 25^{\circ} \mathrm{C}, 23 \%\right.$ humidity) without any lubrication. Experiments were conducted for three pairs of discs for 30,000 cycles at a rotational speed of $100 \mathrm{rpm}$ and $95 \mathrm{rpm}$ respectively with an externally applied load equal to $300 \mathrm{~N}$. Weight losses were measured for three pairs of discs and normalised against load and wear length.

\subsection{Metallography}

Heat treated samples were characterised using scanning electron (Jeol 5800 LV) and transmission electron (Jeol $200 \mathrm{CX}$ ) microscopy depending on the resolution and information required out of the microstructure. For scanning microscopy, the metallographically ground and polished samples were etched with 2 volume $\%$ nital. Thin foils for transmission electron microscopy were prepared by cutting $\sim 200 \mu \mathrm{m}$ thick samples using a $\mathrm{SiC}$ blade, from which discs of $3 \mathrm{~mm}$ diameter were machined out using spark-erosion. The discs were then ground down to $50 \mu \mathrm{m}$ thickness using 2500 and 4000 grit $\mathrm{SiC}$ abrasive papers successively and foils were prepared by electro-polishing at $-4^{\circ} \mathrm{C}$ in an electrolyte comprising of 5\% perchloric acid, $15 \%$ glycerol and $80 \%$ methanol by volume.

Light optical interferometry under vertical shift mode, which is used for irregular surfaces having step heights of the order of few millimetres, was adopted to measure the roughness of the surfaces before and after the wear tests.

\subsection{Nanoindentation tests}

Knoop indenters often fail to measure the hardness of the surface and sub-surface layer after abrasion because of the presence of severe microstructural gradients that require finer resolution than the scale of the indenter $[24,25]$. Constant-depth nanoindentation was therefore used to to characterised changes on cross sections of the wear samples, prepared by polishing with $200 \mathrm{~nm}$ colloidal silica for $5 \mathrm{~min}$. This polishing achieves a surface roughness less than the maximum depth of penetration made by the indenter. An MTS nanoindenter with a Bercovich indenter was used, calibrated via tip truncation after indenting a standard fused silica sample. The depth of penetration was kept constant at $\sim 400 \mathrm{~nm}$ for all the samples and hardness was calculated from the slope of the load-displacement curves using Oliver and Pharr's method [26].

\subsection{X-ray diffraction}

A Philip's PW1730 vertical X-ray diffractometer was used with the Bragg-Brentano geometry under continuous scanning mode over a range of $2 \theta=38^{\circ}-150^{\circ}$ with a scan step of $0.03^{\circ}$ and dwell time of $14 \mathrm{~s}$ per step. The radiation used was $\mathrm{Cu}_{K_{\alpha}}$ so much of the diffracted information comes from a depth of about $1 \mu \mathrm{m}$. The diffracted beam out of the surface was focused on a curved 
graphite monochromator through an anti-scatter slit of $0.2^{\circ}$ and a receiving slit of $0.5^{\circ}$. Together with the quantitative phase analysis, crystallite sizes and lattice microstrains were also estimated. Standard strain-free crystals of $\mathrm{LaB}_{6}$ were diffracted in the same instrument over a $2 \theta$ range of $20-150^{\circ}$ in order to measure the instrumental broadening using the Caglioti equation,

$$
\beta_{\text {standard }}=\sqrt{u \tan ^{2} \theta+v \tan \theta+w}
$$

The Caglioti parameters for $\mathrm{LaB}_{6}$ spectra obtained after full-pattern refinement in XPert HighScore + are $u=0.004531, v=0.000513$ and $w=0.007907$ respectively, parameters used subsequently to calculate instrumental broadening. The broadening ranged between $0.1^{\circ}-0.2^{\circ}$ over the $2 \theta$ range studied. Appropriate values of instrumental broadening ( $\left.\beta_{\text {broadening }}\right)$ have been deduced for each of the peaks austenite and subsequently stripped off from the total broadening $\left(\beta_{\text {measured }}\right)$. However, the individual peak widths were actually a complex addition of both Lorentzian and Gaussian components and therefore, peak widths were calculated twice (Table 4) assuming once a pure Lorentzian and then again assuming a pure Gaussian shape. This resulted in two values each for crystallite size and lattice microstrain, the actual value being somewhere in between these two.

\section{Results and Discussions}

\subsection{Microstructure}

The structure following heat treatment is illustrated in Fig. 1, showing the expected mixture of slender platelets of bainitic ferrite and thin films of austenite, both containing a significant density of dislocations; carbides were not observed over five different locations studied. The mean lineal intercept $(\bar{L})$ was measured in the direction perpendicular to the trace of the habit plane of the bainitic ferrite plates from randomly selected locations of transmission micrographs, in order to estimate the true thickness $(t)$ using the relation [27]:

$$
t=2 \bar{L} / \pi
$$

to be $35 \pm 4 \mathrm{~nm}$.

(a)

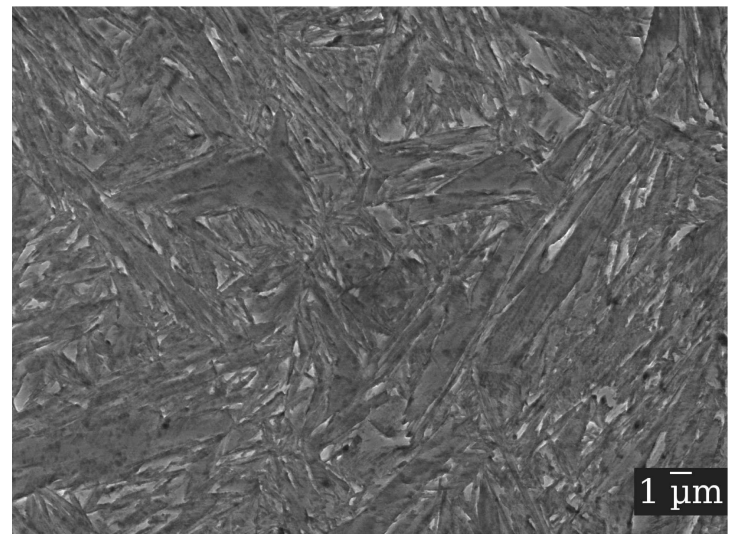

(b)

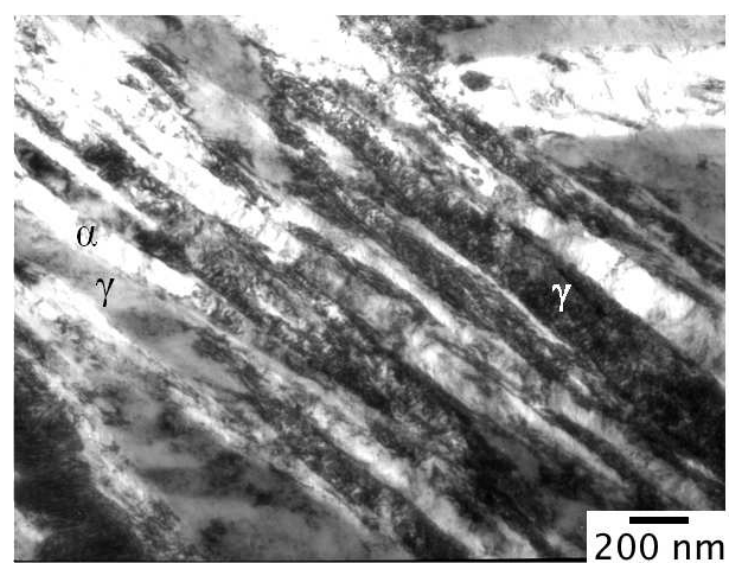

Figure 1: Structure following transformation at $200^{\circ} \mathrm{C}$, (a) scanning electron micrograph, (b) bright-field transmission electron micrograph. 


\subsection{Surface topography}

Fig. 2 shows the interferometry images from the surfaces of discs before and after the rolling/sliding tests. Parallel machining marks identified by steep ridges are evident on the circumference of the discs (Fig. 2a,b). Clearly, the ridges would lead to non-conforming contact between two discs during rolling/sliding, possibly resulting in more of an asperity contact rather than that between two geometrically-smooth cylindrical surfaces in Hertzian contact. There will, therefore, be a running-in period before the contact area increases. This is indicated by the decrease in the overall roughness of the tracks after testing, Fig. 2b,d. The roughness parameters measured before and after wear are listed Table 3 . Though the average roughness, $R_{a}$, was reduced by wear, the maximum height of the scanned profile, $R_{t}$, and average distance between the highest crest and lowest trough, $R_{z}$, nearly doubled. Pits marked as deep blue regions in Fig. 2d could also be the possible sites of material removal apart from the knocked off crests.

Table 3: Surface roughness parameters of discs before and after rolling/sliding.

\begin{tabular}{ccccc}
\hline & Disc & $R_{a} / \mu \mathrm{m}$ & $R_{z} / \mu \mathrm{m}$ & $R_{t} / \mu \mathrm{m}$ \\
\hline \multirow{2}{*}{ Before } & Disc 1 & 1.30 & 6.98 & 7.48 \\
& Disc 2 & 1.27 & 7.04 & 7.17 \\
\multirow{2}{*}{ After } & Disc 1 & 1.08 & 13.91 & 15.23 \\
& Disc 2 & 1.11 & 11.39 & 11.80 \\
\hline
\end{tabular}

\subsection{Wear data}

A specific wear rate is the volume loss per unit load and distance travelled by a point on the perimeter over the duration of test. The rates recorded in the present work are compared against published data $[8,9,23]$ as a function of initial hardness, in Fig. 3. It is evident that in spite of the fact that the alloy studied here (Bainite200) does not have the maximum hardness, the specific wear rate is one of the lowest. That of the much harder alloy designated 09C220 is close to the present work; the 1C-Si alloy [23] has a lower wear rate, but is harder. Bainite200 has more retained austenite $(\sim 27 \mathrm{vol} \%)$ than 09C220 $(\sim 22 \mathrm{vol} \%)$ with similar plate thickness of bainitic ferrite.

\subsection{Contact stress during rolling/sliding}

\subsubsection{Distribution of force over the Hertzian contact width}

The schematic of the twin disc set up is shown in Fig. 4. The discs compressed against each other will initially have a straight line of contact having length equal to the amount of overlap between the discs and the width of the one-half of the contact strip expressed as [28]:

$$
b=2 \sqrt{\frac{1-\nu^{2}}{\pi} \frac{P\left(\frac{1}{E_{1}}+\frac{1}{E_{2}}\right)}{l\left(\frac{1}{R_{1}}+\frac{1}{R_{2}}\right)}}
$$



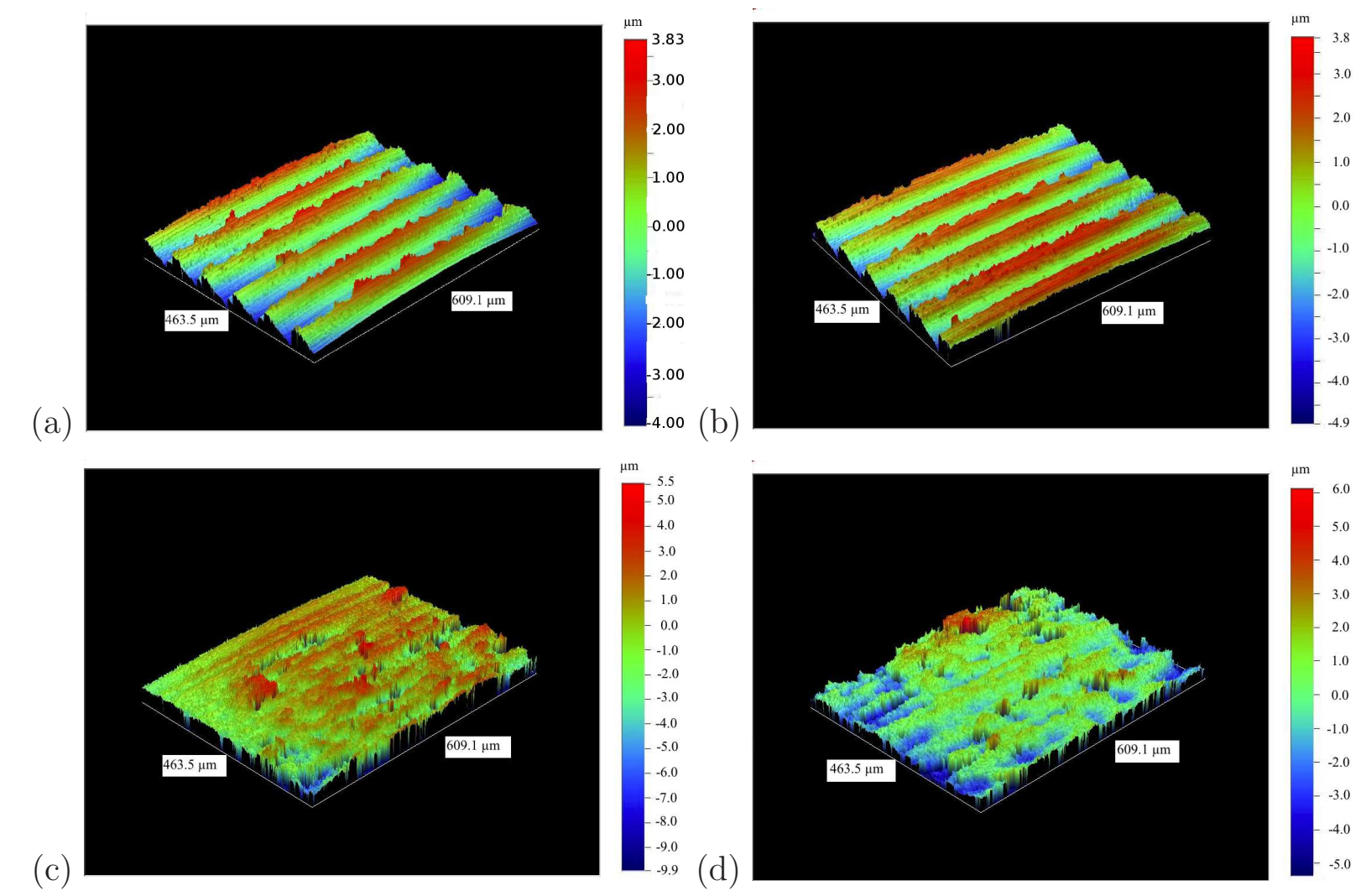

Figure 2: Light interferometry images of the surface of bainitic discs, (a,b) before rolling/sliding, (c,d) after rolling/sliding.

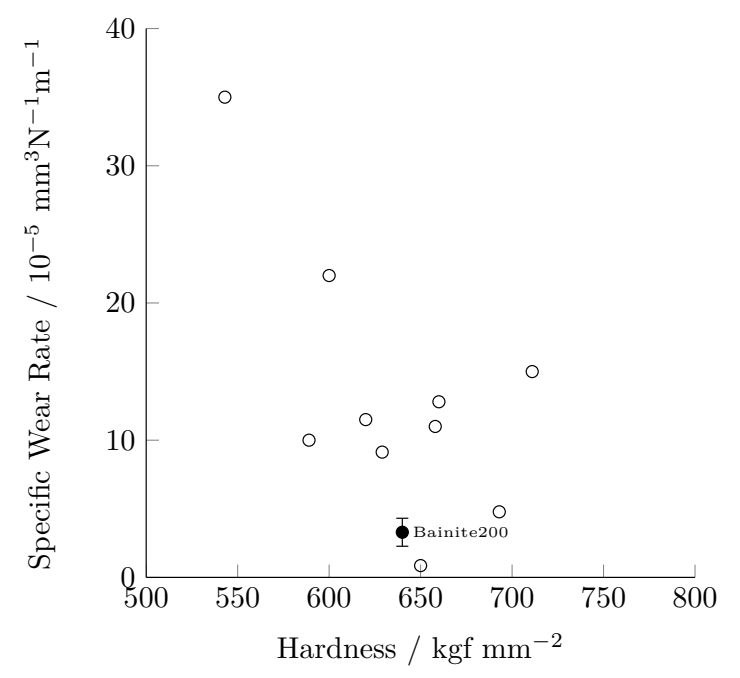

Figure 3: Specific wear rate recorded in the present work (filled dot with error bars, Bainite200), together with published data on other carbide-free bainitic steels $[8,9]$. All the data are from tests with similar conditions of rolling/sliding. 

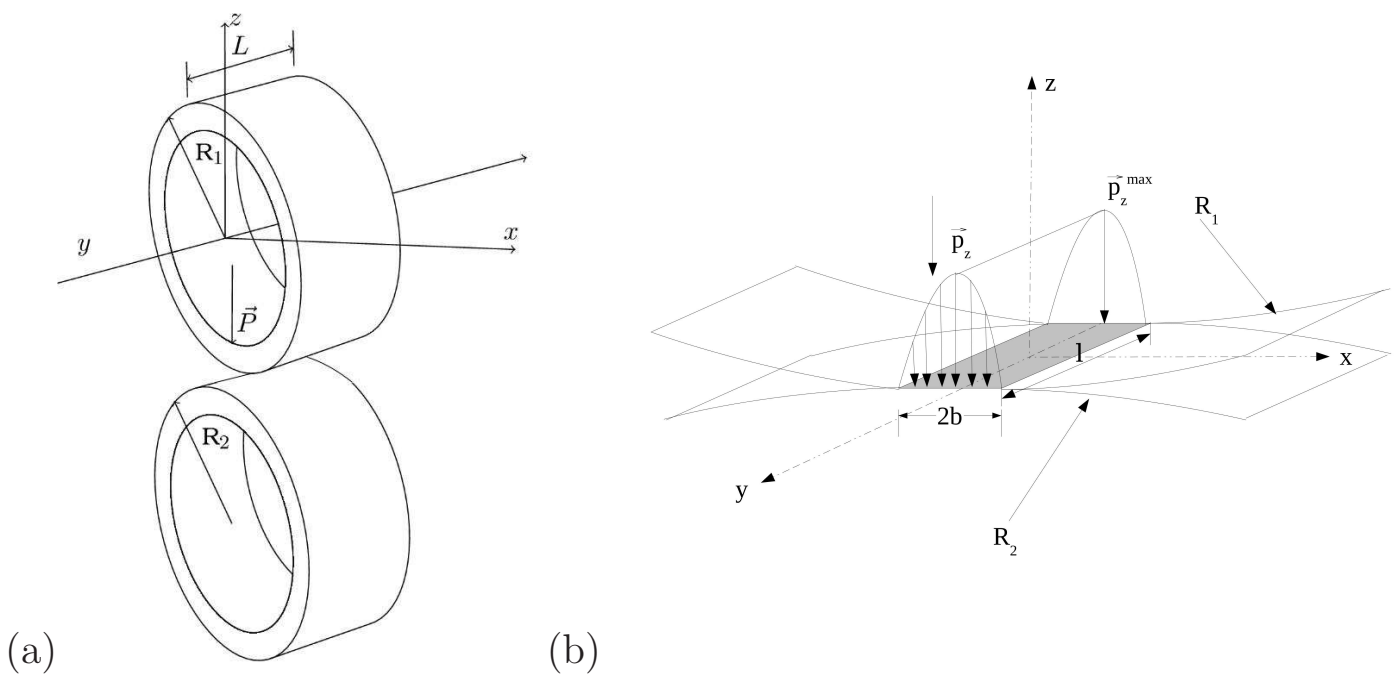

(b)

Figure 4: Schematic of the (a) twin-disc set up, (b) stress distribution over the Hertzian contact.

where

$\begin{array}{ll}\nu=0.3 & \text { Poisson's ratio of the materials in contact } \\ P=300 \mathrm{~N} & \text { applied force on the cylinders } \\ E_{1}=E_{2}=210 \mathrm{GPa} & \text { Young's moduli of the materials in contact } \\ R_{1}=R_{2}=22.5 \mathrm{~mm} & \text { disc radii } \\ l=5 \mathrm{~mm} & \text { length of overlap of discs. }\end{array}$

With equation 3 , this gives $b=86 \mu \mathrm{m}$, so that the full width of the contact strip is $172 \mu \mathrm{m}$. It is of course assumed that the surfaces in contact are geometrically smooth whereas in reality, there are asperities, initially from sample preparation and later from surface damage (Fig. 2). There should nevertheless be a gradual increase in contact area as the test progresses, with consequent decrease in the contact stress towards the calculated values, shown in Fig. 5 for a steady-state overlap of $5 \mathrm{~mm}$.

The normal and tangential distributions of the forces per unit length, over the Hertzian contact zone, for the rolling-sliding condition are given by [28, p. 204], where the coordinate $z$ is parallel to the normal load, and $x$ to the direction of sliding:

$$
p_{z}=\frac{2 P}{\pi l b^{2}} \sqrt{b^{2}-x^{2}}, \quad|x| \leq b
$$

which leads to a parabolic distribution of the normal force per unit length, over the Hertzian contact width as shown in Fig. 5. The tangential components depend also on the roll-slide parameter and the size $b_{1}$ of the slide zone, [29]:

$$
p_{x}= \begin{cases} \pm \frac{2 \mu P}{\pi l b^{2}} \sqrt{b^{2}-x^{2}}, & |x| \leqslant b,\left|x-b+b_{1}\right|>b_{1}, \\ \pm \frac{2 \mu P}{\pi l b^{2}}\left[\sqrt{b^{2}-x^{2}}-\sqrt{b_{1}^{2}-\left(x-b-b_{1}\right)^{2}}\right], & |x| \leqslant b,\left|x-b+b_{1}\right| \leqslant b_{1} .\end{cases}
$$

where the negative sign is for the shear along the sliding direction, $\mu$ is the dynamic coefficient of friction and $b_{1}$ is the half-width of the slide zone (Fig. 4). Integrating equation 5 over the contact 


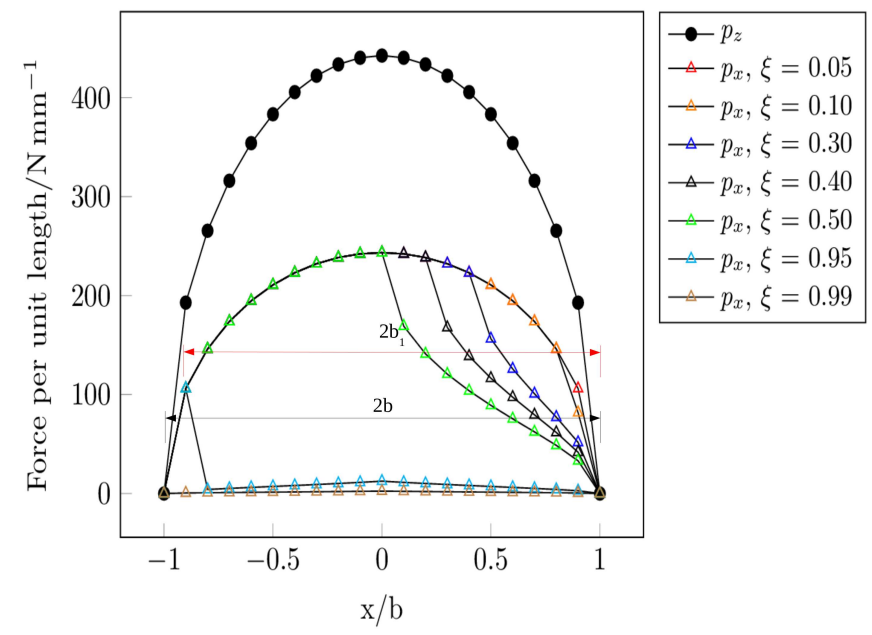

Figure 5: Distribution of normal $\left(p_{z}\right)$, and tangential force $\left(p_{x}\right)$ over the Hertzian contact half-width for $\xi=$ $0.05,0.20,0.40,0.50,0.95$ and 0.99 during rolling-sliding assuming a contact length equal to $5 \mathrm{~mm}$. Hertzian contact width $(2 b)$ and width of the slide zone $\left(2 b_{1}\right)$ for $\xi=0.95$ are indicated respectively.

width $b,-b$ yields the size of the slide zone as:

$$
\frac{b_{1}}{b}=\left(1-\frac{p_{t}}{\mu p_{n}}\right)^{\frac{1}{2}} \quad \text { with } p_{t}=\text { tangential load per unit length }
$$

which on substitution into equation 5 gives [29]:

$$
p_{x}(x)= \begin{cases}\frac{2 \mu p_{n}}{\pi b} \sqrt{1-\left(\frac{x}{b}\right)^{2}}, & -b \leqslant x<b-2 b \xi, \\ -\frac{2 \mu p_{n}}{\pi b}\left[\sqrt{1-\left(\frac{x}{b}\right)^{2}}-\sqrt{\xi^{2}-\left(\xi+\frac{x}{b}-1\right)^{2}}\right], & b-2 b \xi \leqslant x \leqslant b .\end{cases}
$$

$p_{n} / b$, can be taken as constant for a fixed load and length of overlap. In our experiment, the dynamic coefficient of friction was found to be $\mu=0.55$ after reaching steady state conditions. The set of equations was solved numerically as a function of $\xi$, and the resulting distributions of $p_{x}$ are plotted in Fig. 5. This asymmetry of the tangential force results in skewed distribution of normal, shear and von Mises stress near surface and subsurface, as described in following section.

The normal and shear stresses $\sigma_{z}, \sigma_{x}$ and $\tau_{x z}$, due to the combined effect of the distributed normal and tangential forces $p_{z}$ and $p_{x}$, acting on the Hertzian contact width are then obtained as described in detail in [29]. The necessary integrals were solved numerically, and some computations are presented in Fig. 6 for a variety of conditions. It is evident that sliding causes a major change and asymmetry in the distribution of stresses. The results illustrated will be used to interpret measured gradients in properties, later in the paper.

\subsection{Scanning electron microscopy}

Fig. 7a shows the typical worn surface after rolling/sliding. Tracks of wear marks could be seen along with ledges protruding from the edge, indicating significant plasticity of the deformed 
(a)

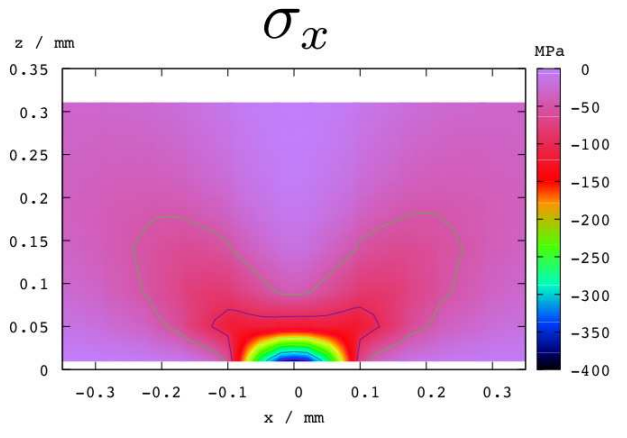

(b)

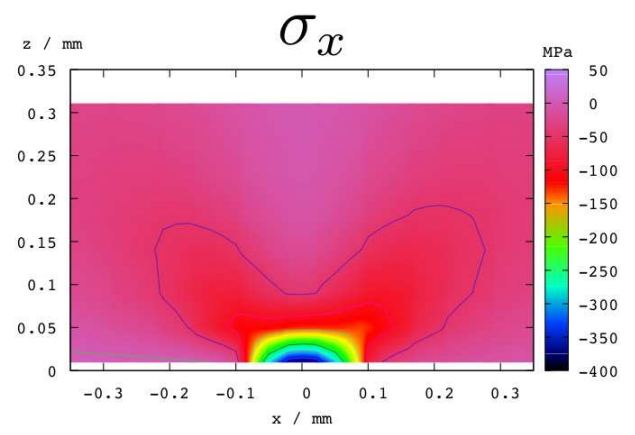

(d)

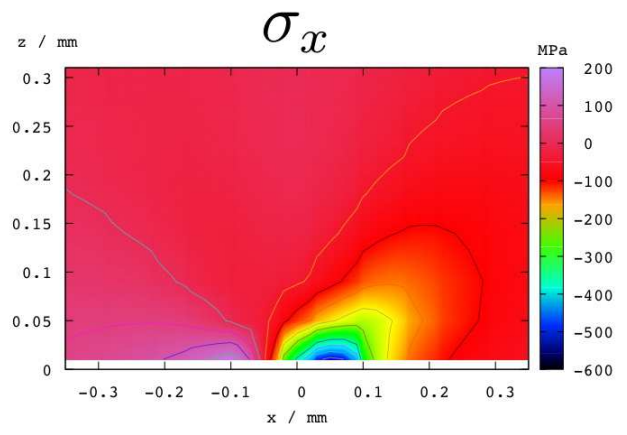

(g)

(h)

(e)

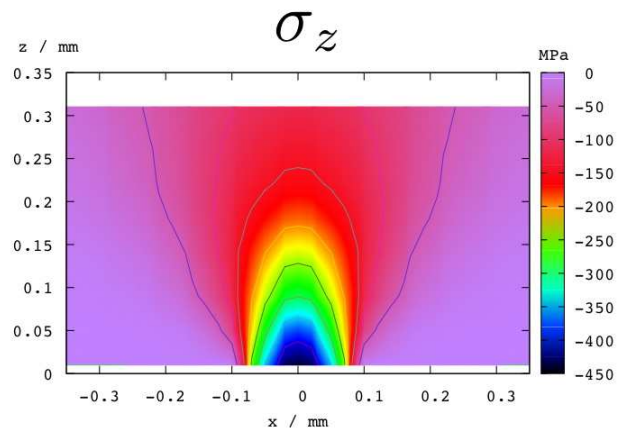

(c)
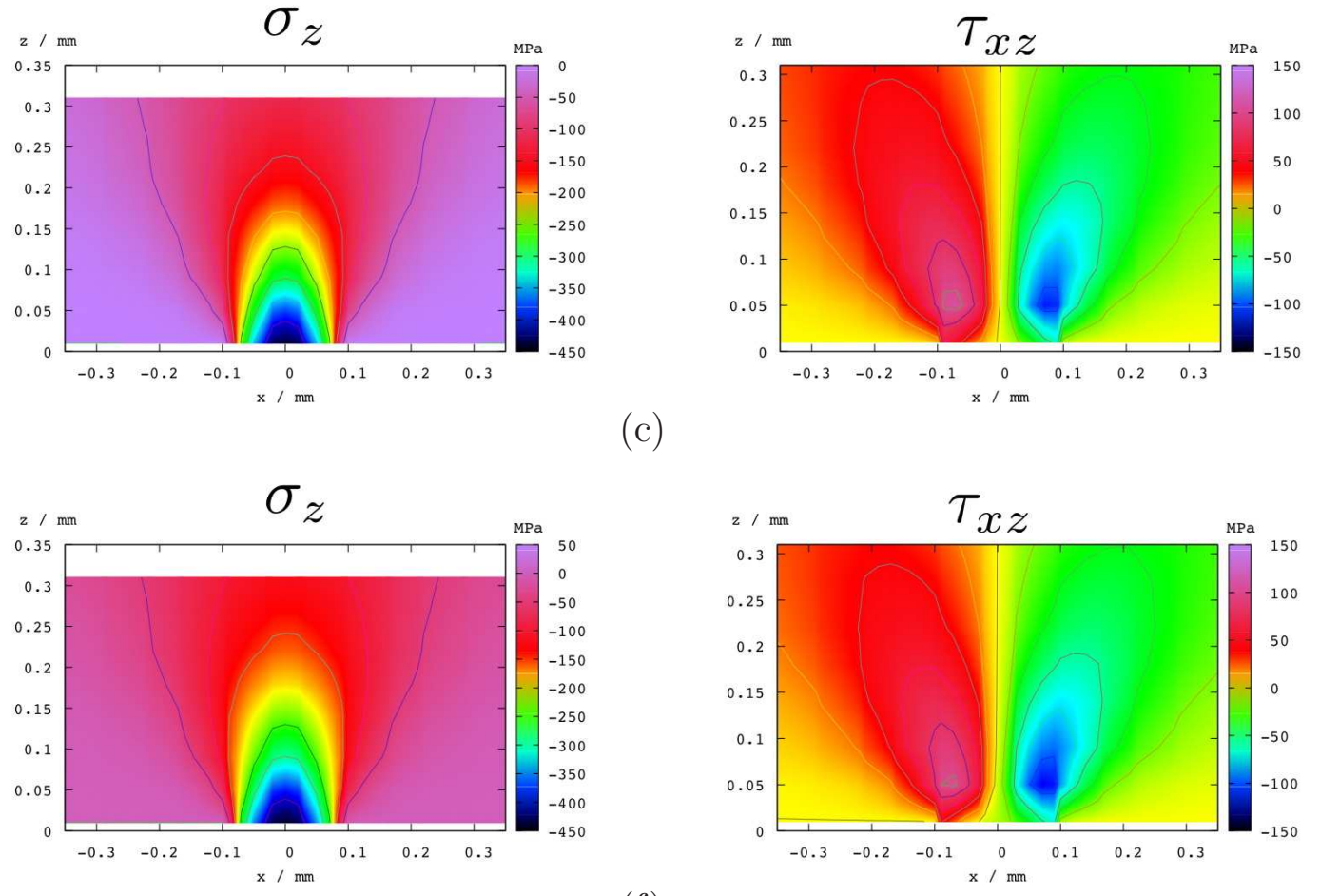

(f)
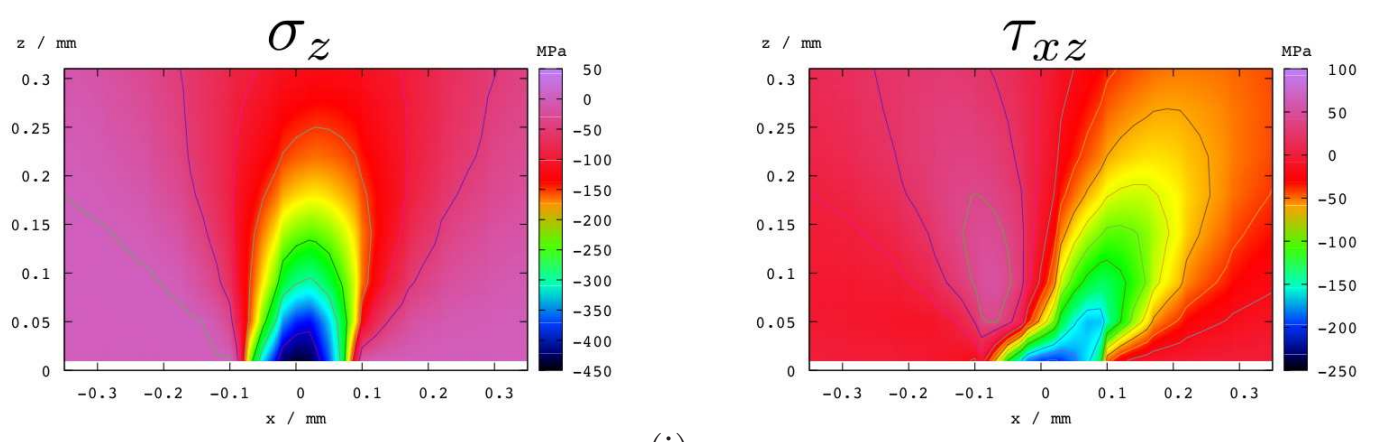

(i)

Figure 6: Calculation of tractional stress $\sigma_{x}$, normal stress $\sigma_{z}$ and shear stress $\tau_{x z}$ for $l=5 \mathrm{~mm}$. (a-c) Assuming perfect rolling, (d-f) roll-slide parameter $\xi=0.95$, assuming marginal slip, and (g-i) assuming perfect sliding of rolling/sliding cylinders. 
material on the surface. The surface morphology is quite different from previous work [7-9], where extensive delamination, surface cracking and indentations were found. Almost no wear debris, in the form of metallic flakes was found to be attached on the surface. Therefore, 'type III' wear, which occurs due to mutual abrasion of wear debris generated during initial running-in period was missing in this case [30]. Fig. 7b shows the cross section of the worn surface; there is a little damage to the nanostructure, with only a sparse distribution of what could be microscopic voids or sub-surface fatigue cracks, as observed in case of other bainitic steels[8,9]. The extent of the deformed layer beneath the surface is also limited with $a \leqslant 5 \mu \mathrm{m}$ non-etching layer that has formed as shown in Fig. 7c. This layer indicates onset of wear, exactly matching with the location where maximum tractional stress $\sigma_{x}$ is experienced. The layer is quite adherent to the underlying material, continuous and with very limited porosity. The temperature at the mating surfaces during rolling/sliding was close to room temperature and therefore possible reaustenitisation followed by martensitic transformation can be negated. Non-etching layers of the type observed here are a typical reflection of intense, repeated deformation, grain fragmentation and mechanical homogenisation [31].

The intense deformation due to the traction of rolling/sliding remains limited with in $\sim 5 \mu \mathrm{m}$ of the surface and decreases sharply thereafter. This is a striking feature of this particular nanostructured bainite studied here compared to earlier work $[8,9]$ where samples were tested under similar conditions. Leiro et al. found significant deformation of the microstructure, up to $20 \mu \mathrm{m}$ from the wear surface, together with fatigue cracks and porosity in the microstructure $[8,9]$; the results were explained by adhesion and subsequent elastic-plastic deformation of surface asperities augmenting a microscopic three-body abrasion effect. The observations are consistent with the fact that the wear rate recorded is the smallest of all the data presented in Fig. 3, in spite of the fact that the material is not the hardest available. It can only be speculated that the work-hardening capacity of the present material is large enough to limit the depth of deformation

\subsection{Nanoindentation tests}

Nanohardness values measured on the polished cross-sectional specimen are plotted against the distance below the contact surface in Fig. 8. Significant hardening is detected under the surface, at a depth of some 40-50 $\mu \mathrm{m}$. This is an important observation in the context of the calculations presented in Fig. 6, where the maximum shear stress under rolling-sliding conditions is predicted to be at approximately this depth. In contrast, if sliding plays a role in the process of wear, then the maximum shear stress is at the surface. This combination of results gives a clear interpretation that the mechanism of wear in the present case does not involve sliding, but rather, just rolling and sliding. This results in contact shear-stresses that by Hertzian theory would be a maximum below the contact surfaces. As a result, the mechanism of wear may involve both that due to the sliding component and possible due to damage caused by the sub-surface stresses leading eventually to detachment.

It is worth comparing the present data with previous work on carbide-free bainite. The earlier work [9] noted that adhesion contributed to the wear process, and that cracks were observed to initiate from the surface, with delamination contributing to the damage. In these circumstances, it is not surprising that the depth of the deformation zone was larger than in the present case. Although the steels studied [9] have a similar structure to the nanostructured bainite observed, there could be a number of explanations for the difference in behaviour. In particular, Fig. 8 shows sub-surface hardening coincident with the depth at which the maximum shear stress occurs during rolling contact - the hardness has increased to some $750 \mathrm{HV}$, possibly due to the stress-induced 


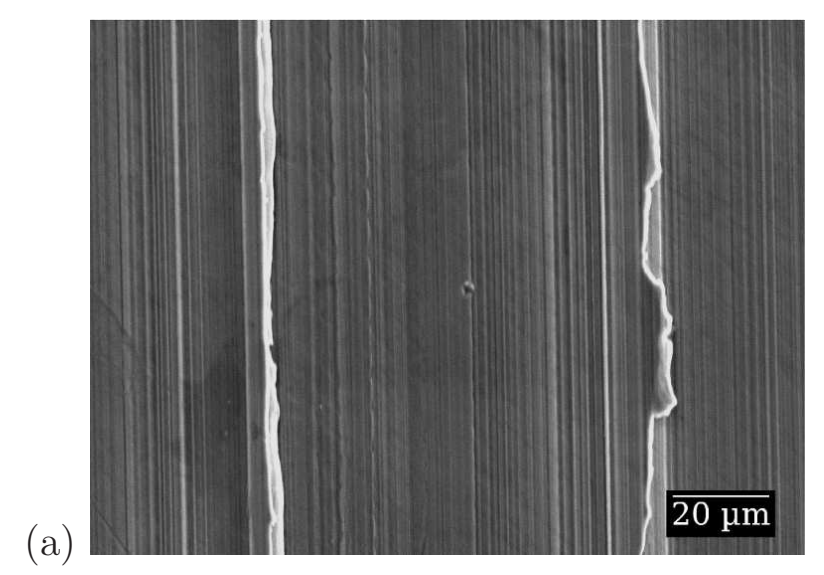

(b)
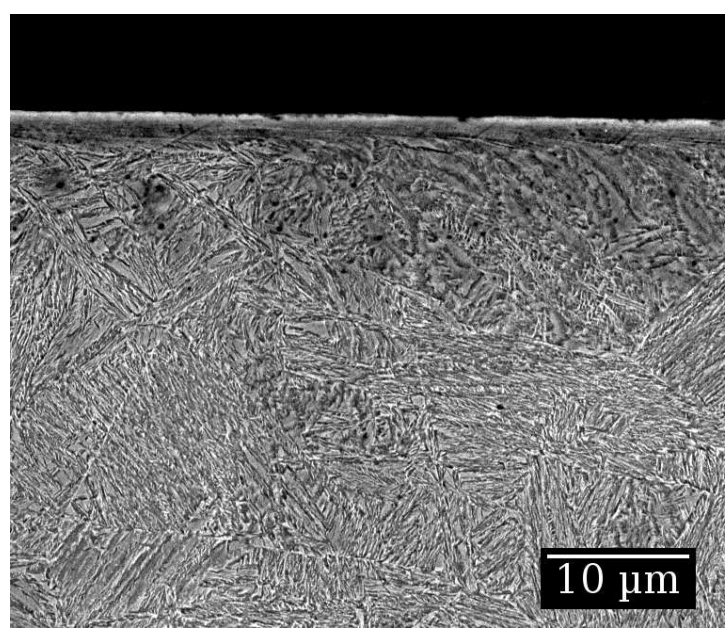

(c)

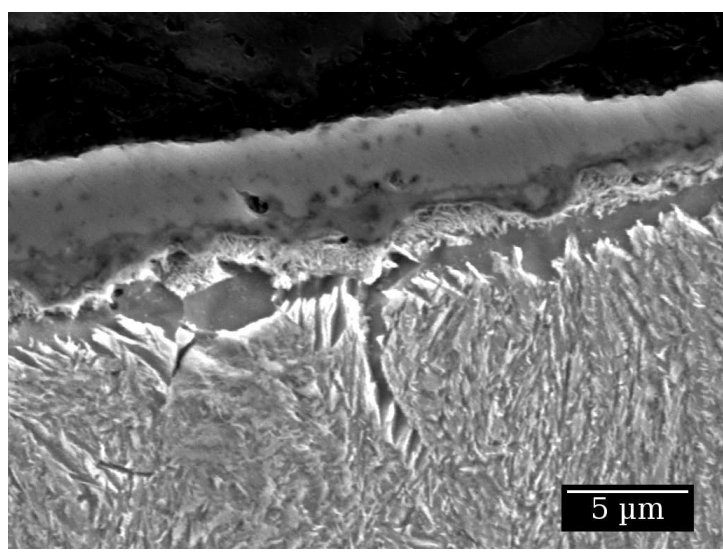

Figure 7: Structure after rolling-sliding (a) showing wear tracks on the surface with ledges indicating plastic deformation of the surface, (b) limited subsurface deformation of the microstructure in the direction of rolling/sliding and (c) a very thin non-etching layer on the surface. 
transformation of retained austenite into hard martensite. This would make the material more resistant to rolling contact damage since the fine martensite that forms from the thin films of austenite in the present alloy would resist cracking [32]. Therefore, the mechanical stability and size-scale of the austenite could vary as a function of alloy content, and it is noteworthy that all the alloys reported in [9] were transformed at a higher temperature and for shorter times, leaving the possibility of blocky austenite or the presence of some martensite in the initial structure.

It will also be seen from the X-ray data on the present alloy, that while the austenite at the very surface of the sample undergoes some transformation, the majority of it remains stable, which would add to the ductility and toughness of the surface layer.

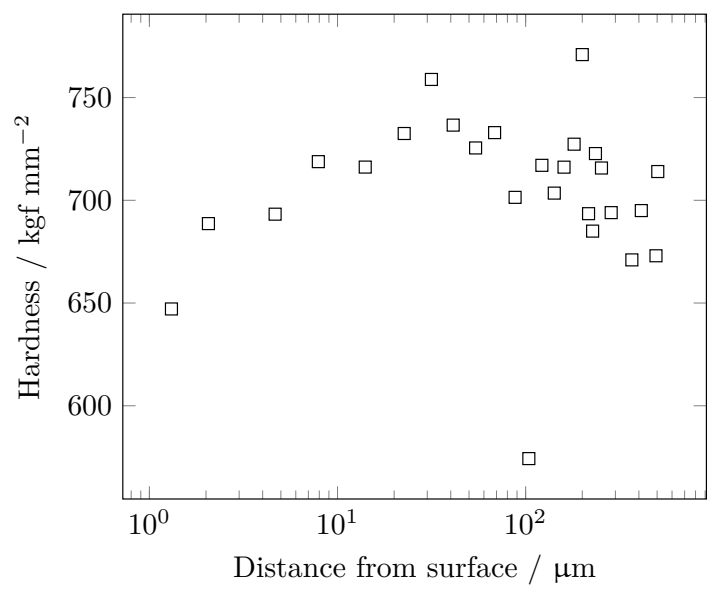

Figure 8: Distribution of nanohardness of the surface and subsurface layers after rolling/sliding as measured by nanoindentation.

\subsection{X-ray diffraction}

X-ray diffraction spectra taken before and after wear tests are illustrated in Fig. 9 and the quantitative phase analysis using full pattern Rietveld analysis using both X'Pert HighScore+ and MAUD[33] is listed in Table 4.

Individual reflections from the diffracting planes of fcc-austenite and bcc-ferrite are labeled in the Fig. 9. Bragg reflections from the $\{110\}_{\alpha},\{200\}_{\alpha},\{211\}_{\alpha},\{220\}_{\alpha},\{310\}_{\alpha}$ and $\{222\}_{\alpha}$ planes along with $\{200\}_{\gamma},\{220\}_{\gamma}\{311\}_{\gamma}$ reflections could be identified over the scanned $2 \theta$ range. Peaks of bcc-ferrite and bct-martensite had less than $0.1^{\circ}$ separation and therefore could not be deconvoluted. As the temperature during rolling/sliding did not go beyond $29^{\circ} \mathrm{C}$, the possibility of re-austenitisation of ferrite and subsequent transformation to martensite is neglected.

The relative intensity of the austenite peaks was diminished after wear testing, indicating stressaffected transformation into martensite. It is interesting, however, that the decrease in content was from $27.9 \pm 0.4 \mathrm{vol} \%$ to $17.3 \pm 0.3 \mathrm{vol} \%$, meaning that the majority of the austenite remains stable under conditions where there is intense deformation at the surface. This is undoubtedly a consequence of a phenomenon known as mechanical stabilisation [34, 35], where the plastic deformation of austenite prevents martensitic transformation because the latter requires the existence of a glissile interface. It is likely that the effect is exaggerated by the fact that the austenite is present in a finely divided state - a reduction in the grain size of austenite reduces its martensite-start temperature [36, 37]. 


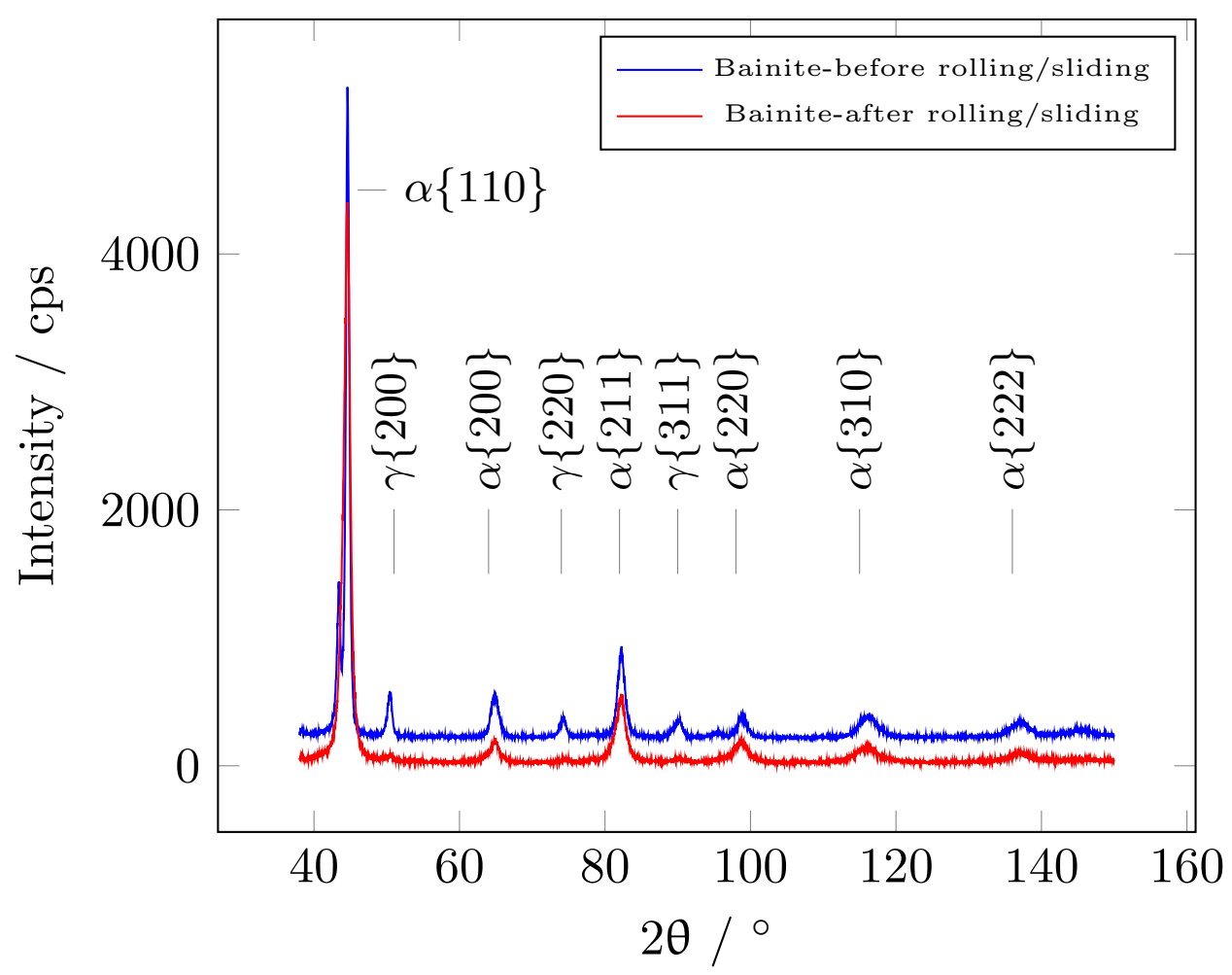

Figure 9: X-ray diffraction of bainite before and after rolling/sliding indicating strain induced transformation of retained austenite.

The broadening of diffraction peaks was studied to assess further the structural changes due to wear, associated with the retained. The Williamson-Hall plots in Fig. 10 are able to separate the size of coherent domains from heterogeneous strains due to defects in the material [38]. The quantitative data listed in Table 4; they are interesting in that they show that the extent of heterogeneous strain due to defects such as dislocations has not change sufficiently to mechanically stabilise austenite. Instead, the size of the austenite regions has been greatly refined, presumably by the formation of some martensite. Our calculations [37] indicate that such a refinement would lead to a dramatic decrease in the martensite-start temperature. A calculation using the method described in [39] shows a drop in martensite start temperature from $-54{ }^{\circ} \mathrm{C}$ to $-70{ }^{\circ} \mathrm{C}$ as coherent size of the austenite is reduced from $20 \mathrm{~nm}$ to $6 \mathrm{~nm}$. It is concluded therefore that the stabilisation of the austenite must occur at the early stages of deformation, by plates of martensite sub-dividing the regions of austenite. 


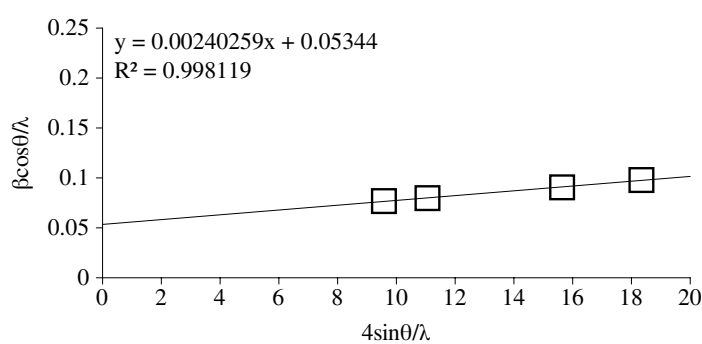

(a)

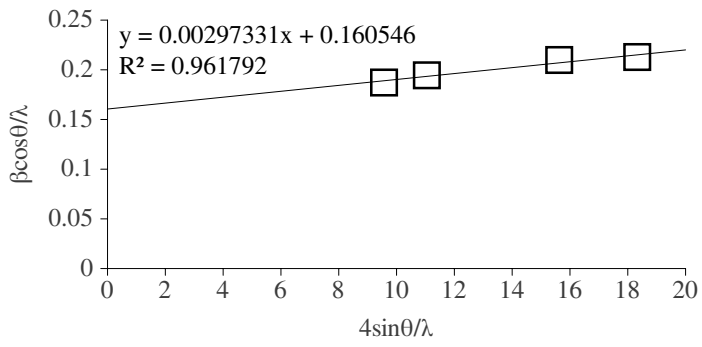

(c)

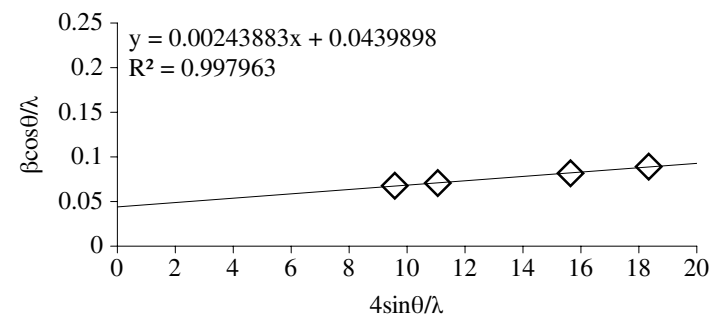

(b)

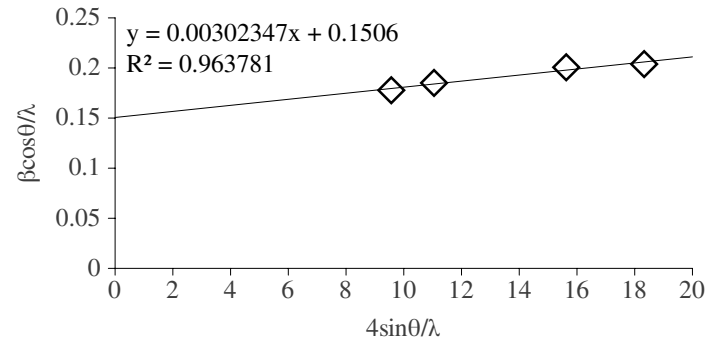

(d)

Figure 10: Williamson-Hall plot for austenite (a) before rolling/sliding assuming Gaussian peak broadening, (b) before rolling/sliding assuming Lorentzian peak broadening, (c) after rolling/sliding assuming Gaussian peak broadening and (d) after rolling/sliding assuming Lorentzian peak broadening.

Table 4: Volume percent of austenite $V_{\gamma}$, crystallite size $D$ and microstrain $\varepsilon$ data, the latter presented for both the Gaussian and Lorentzian peak shapes. The $\{200\},\{220\}$ and $\{311\}$ reflections of austenite were included in the analysis.

\begin{tabular}{lccccc}
\hline & & \multicolumn{2}{c}{ Gaussian } & \multicolumn{2}{c}{ Lorentzian } \\
& $V_{\gamma}$ & $D$ & $\varepsilon$ & $D$ & $\varepsilon$ \\
\hline Before wear & $27.9 \pm 0.4$ & 16.5 & 0.0014 & 20.0 & 0.0009 \\
After wear & $17.3 \pm 0.3$ & 6.0 & 0.0016 & 6.4 & 0.0011 \\
\hline
\end{tabular}




\section{Conclusions}

The wear of nanostructured mixture of bainitic ferrite and carbon-enriched retained austenite under rolling-sliding conditions has been studied, and the following general conclusions can be drawn from the combination of experimental work and theoretical analysis:

1. The fine structure produced by isothermal transformation at $200^{\circ} \mathrm{C}$ exhibits one of the lowest specific wear rates of any carbide-free bainite studied previously under similar circumstances. The significant difference here, apart from the $35 \mathrm{~nm}$ scale of the structure, is that the retained austenite content is about $27 \%$. This provides a mechanism of work hardening that leads to an increase in hardness in the affected zone. It is recognised however, that a particular alloy, 06CV reported by Sourmail et al. [23] has lower wear rate (Table 1). However, this assumes that the laboratory melt ('06CV') and industrial ('06CV-indus') have identical behaviour and that the hardness is about $610 \mathrm{HV}$. It further assumes that the alloy is indeed the carbidefree nanostructured bainite, although there are no transmission electron microscopy data to confirm this.

2. Rolling/sliding calculations suggest that in the absence of sliding, the maximum shear stresses should occur at a depth of about $50 \mu \mathrm{m}$ below the contact surface, whereas pure sliding would lead to the maximum located at zero depth. Experimental results show that there is a significant peak in nanohardness developed, also at a depth of about $50 \mu \mathrm{m}$, indicating that sliding did not play a significant role in the mechanism of wear.

3. The absence of sliding under the conditions studied is consistent with the very low specific wear rate observed, and the topology of the wear surface following the tests.

4. The subsurface hardening mechanism will, as indicated by X-ray analysis, involve some transformation of the austenite into hard martensite, contributing to the change in hardness from about 650 to more than $750 \mathrm{kgf} \mathrm{mm}^{-2}$. The sub-surface hardened regions did not reveal any evidence of damage, probably because any martensite that forms is itself very fine, and because the austenite that remains is mechanically stabilised to further transformation.

5. The work demonstrates a clear role of structure in the optimisation of wear by the mechanism believed to operate here. A general conclusion therefore, is that in addition to hardness, wear can be reduced by engineering the structure to contain some stable austenite, the stability of which is determined not just by a high carbon concentration, but also its fine scale. These results are relevant to the design of novel bearing steels based on nanostructured, carbide-free bainite, particularly because sliding has been avoided under dry conditions.

The source code written to solve the contact stress during rolling/sliding can be found in http://www.msm.cam.ac.uk/phase-trans/2014/rolling_sliding.zip.

Acknowledgements: SDB thanks Tata Steel Limited, India for generously funding this project. Rolling/sliding tests conducted at the department of applied physics and mechanical engineering, Luleå University of Technology, Sweden is duly acknowledged. 


\section{References}

[1] P. J. Mutton. The influence of microstructure of the wear behavior of rail and wheel materials. M.app.sc. thesis, University of Melbourne, 1985.

[2] R. Devanathan and P. Clayton. Rolling-sliding wear of three bainitic steels. Wear, 151:255-267, 1991.

[3] J. E. Garnham and J. H. Beynon. Dry rolling-sliding wear of bainitic and pearlitic steels. Wear, 157:81-109, 1992.

[4] P. Clayton and N. Jin. Unlubricated sliding and rolling/sliding wear behavior of continuously cooled low/medium carbon bainitic steels. Wear, 200:74-82, 1996.

[5] N. Jin and P. Clayton. Effect of microstructure on rolling/sliding wear of low carbon bainitic steels. Wear, 202:202-207, 1997.

[6] K. M. Lee and A. A. Polycarpou. Wear of conventional pearlitic and improved bainitic rail steel. Wear, 259:391-399, 2005.

[7] L. C. Chang. The rolling/sliding wear performance of high silicon carbide-free bainitic steels. Wear, 258:730-743, 2005.

[8] A. Leiro, A. Kankanala, E. Vuorinen, and B. Prakash. Tribological behaviour of carbide-free bainitic steel under dry rolling/sliding conditions. Wear, 273:2-8, 2011.

[9] A. Leiro, E. Vuorinen, K. G. Sundin, B. Prakash, T. Sourmail, V. Smanio, F. G. Caballero, C. GraciaMateo, and R. Elvira. Wear of nano-structured carbide-free bainitic steels under dry rolling-sliding conditions. Wear, 298-299:42-47, 2013.

[10] H. Masumoto, K. Sugino, and H. Hayashida. Development of wear resistant and anti-shelling high strength rails in japan. In Heavy Haul Railway Conf., Perth,Australia, September 1978. Institute of Engineers.

[11] W. Heller and R. Schweitzer. Hardness, microstructure and wear behaviour of rail steels. In 2nd Int. Conf. Heavy Haul Railways, Colorado Springs, USA, pages 282-286, 1982.

[12] H. Ichinose, J. Takehara, and M. Ueda. High strength rails produced by two-stage flame heating and slack-quenching. In 2nd Int. Conf. on Heavy Haul Railways, Colorado Springs, USA, pages 178-182, 1982.

[13] J. Kalousek, D. M. Fegredo, and E. E. Laufer. The wear resistance and worn metallography of pearlite, bainite and tempered martensite rail steel microstructure of high hardness. In K. C. Ludema, editor, Proceedings of the 6th International Conference on Wear of Material,, pages 212-231, New York, USA, 1987. American Society of Mechanical Engineers.

[14] J. Kalousek, D. M. Fegredo, and E. E. Laufer. The wear resistance and worn metallography of pearlite, bainite, and tempered martensite rail steel microstructure of high hardness, pages 212-231. American Society of Mechanical Engineers, New York, editor K. C. Ludema, 1985b.

[15] H. K. D. H. Bhadeshia. Bainite in Steels, 2nd edition. Institute of Materials, London, U.K., 2001.

[16] F. G. Caballero, H. K. D. H. Bhadeshia, K. J. A. Mawella, D. G. Jones, and P. Brown. Very strong, low-temperature bainite. Materials Science and Technology, 18:279-284, 2002.

[17] F. G. Caballero and H. K. D. H. Bhadeshia. Very strong bainite. Current Opinion in Solid State and Materials Science, 8:251-257, 2004. 
[18] H. K. D. H. Bhadeshia. The first bulk nanostructured metal. Science and Technology of Advanced Materials, 14:014202, 2013.

[19] T. S. Wang, J. Yang, C. J. Shang, X. Y. Li, B. Lv, M. Zhang, and F. C. Zhang. Sliding frction surface microstructure and wear resistance of $9 \mathrm{SiCr}$ steel with low-temperature austempering treatment. Surface \&3 Coatings Technology, 202:4036-4040, 2008.

[20] P. Zhang, F. C. Zhang, Z. G. Yan, T. S. Wang, and L. H. Qian. Wear property of low-temperature bainite in the surface layer of a carburized low carbon steel. Wear, 271:697-704, 2011.

[21] J. Yang, T. S. Wang, B. Zhang, and F. C. Zhang. Sliding wear resistance and worn surface microstructure of nanostructured bainitic steel. Wear, 282-283:81-84, 2012.

[22] S. Das Bakshi, P. H. Shipway, and H. K. D. H. Bhadeshia. Three-body abrasive wear of fine pearlite, nanostructured bainite and martensite. Wear, 308:46-53, 2013.

[23] T. Sourmail, F. G. Caballero, C. Garcia-Mateo, V. Smanio, C. Ziegler, M. Kuntz, R. Elvira, A. Leiro, E. Vuorinen, and T. Teeri. Evaluation of potential of high Si high C steel nanostructured bainite for wear and fatigue applications. Materials Science and Technology, 29:1166-1173, 2013.

[24] F. Katsuki and M. Yonemura. Subsurface characteristics of an abraded Fe-0.4 wt\%C pearlitic steel: A nanoindentation study. Wear, 263:1575-1578, 2007.

[25] B. K. Prasad and S. V. Prasad. Abrasion-induced microstructural changes during low stress abrasion of a plain carbon $(0.5 \%$ c) steel. Wear, 151:1 - 12, 1991.

[26] W. C. Oliver and G. M. Pharr. Measurement of hardness and elastic modulus by instrumented indentation: Advances in understanding and refinements to methodology. Journal of Materials Research, 19:3-20, 2004.

[27] L. C. Chang and H. K. D. H. Bhadeshia. Austenite films in bainitic microstructures. Materials Science and Technology, pages 874-881, 1995.

[28] K. L. Johnson. Contact Mechanics. Cambridge University Press, Cambridge, U. K., 1985.

[29] L. WenTao, Y. Zhang, F. ZhiJing, and Z. JingShan. Effects of stick-slip on stress intensity factors for subsurface short cracks in rolling contact. Science China Technological Sciences, 56:2413-2421, 2013.

[30] P. Clayton and R. Devanathan. Rolling/sliding wear behavior of a chromium-molybdenum rail steel in pearlitic and bainitic conditions. Wear, 156:121 - 131, 1992.

[31] H. K. D. H. Bhadeshia. Steels for bearings. Progress in Materials Science, 57:268-435, 2012.

[32] S. Chatterjee and H. K. D. H. Bhadeshia. TRIP-assisted steels: cracking of high carbon martensite. Materials Science and Technology, 22:645-649, 2006.

[33] L. Lutterotti. Total pattern fitting for the combined size-strain-stress-texture determination in thin film diffraction. Nuclear Inst. and Methods in Physics Research B, 268:334-340, 2010.

[34] J. R. Strife, M. J. Carr, and G. S. Ansell. Effect of austenite prestrain above the $\mathrm{M}_{d}$ temperature on the $\mathrm{M}_{s}$ temperature in Fe-Ni-Cr-C alloys. Metallurgical Transactions A, 8A:1471-1484, 1977.

[35] S. Chatterjee, H. S. Wang, J. R. Yang, and H. K. D. H. Bhadeshia. Mechanical stabilisation of austenite. Materials Science and Technology, 22:641-644, 2006.

[36] P. J. Brofman and G. S. Ansell. On the effect of fine grain size on the martensite-start temperaure in Fe-27Ni-0.025C alloys. Metallurgical Transactions A, 14A:1929-1931, 1983. 
[37] H. S. Yang and H. K. D. H. Bhadeshia. Austenite grain size and the martensite-start temperature. Scripta Materialia, 60:493-495, 2009.

[38] G. K. Williamson and W. H. Hall. X-ray line broadening from filed aluminium and wolfram. Acta Metallurgica, 1:22-31, 1953.

[39] H.-S. Yang, D. W. Suh, and H. K. D. H. Bhadeshia. More complete theory for the calculation of the martensite-start temperature in steels. ISIJ International, 52:162-164, 2012. 